\title{
Who should you vote for? Empirical evidence from Portuguese local governments
}

\section{Ricardo Duque Gabriel ${ }^{1}$ (1)}

Received: 1 October 2018 / Accepted: 6 March 2019 / Published online: 15 April 2019

(C) ISEG - Instituto Superior de Economia e Gestão 2019

\section{Abstract}

The economic literature considers voters quasi-rational agents that care about maximizing their individual welfare when deciding on who to vote for. Voters believe that, once a politician is elected, his or her characteristics will affect policy outcomes and consequently their private welfare. To assess whether mayors' characteristics influence municipalities' financial performance, I use a dataset composed of 278 Portuguese mainland municipalities from 2003 to 2016. I find that mayors' age, education, occupation, and tenure influence the level of public investment, tax revenues, debt, and budget balances. Although most of the Portuguese voters only consider candidates' political affiliation when deciding on who to vote for, my estimates do not show any significant impact of this characteristic on the financial indicators analyzed. Therefore, these results question the way Portuguese vote by arguing that, when voting for local government representatives, they should care about other characteristics among candidates besides their political affiliation.

Keywords Elections ' Local governments ' Mayors ' Portugal ' Public finance · Voting

Electronic supplementary material The online version of this article (https://doi.org/10.1007/s10258-019-00158-z) contains supplementary material, which is available to authorized users.

Ricardo Duque Gabriel

ricardo.gabriel@uni-bonn.de

1 Department of Economics, University of Bonn, Kaiserstraße 1, Bonn, Germany 